\title{
Postoperative pain management following ambulatory anesthesia: challenges and solutions
}

This article was published in the following Dove Press journal:

Ambulatory Anesthesia

13 January 2015

Number of times this article has been viewed

\author{
Stephan A Schug 1,2 \\ Chandani Chandrasena ${ }^{2}$ \\ 'School of Medicine and \\ Pharmacology, The University of \\ Western Australia, Perth, Australia; \\ ${ }^{2}$ Department of Anesthesia and Pain \\ Medicine, Royal Perth Hospital, Perth, \\ WA, Australia
}

\begin{abstract}
Worldwide, there is an increasing trend toward performing more and more complex surgery in an ambulatory setting, partially driven by economic considerations. Provision of appropriate pain relief is still often inadequate in this setting; poor pain control and adverse effects of opioids provided for pain control are common reasons for readmission, with human and economic consequences. Therefore, improved analgesia after ambulatory surgery is an important goal; appropriate strategies include identification of at-risk patients, provision of multimodal analgesia, and early use of rescue strategies. Multimodal analgesia is based on the combined use of multiple medications or techniques for pain control, which have different mechanisms of action or act on different sites at the pain pathways. Thereby, such an approach improves analgesia, reduces opioid requirements, and reduces adverse effects of opioids. Important components of multimodal analgesia are nonopioids (acetaminophen and anti-inflammatory drugs), corticosteroids, and alpha-2-delta modulators (gabapentin, pregabalin), but most importantly the use of local and regional anesthesia techniques. Here, the use of adjuvants is one way to increase the duration of pain relief, but, increasingly, continuous peripheral nerve blocks via catheters are used in ambulatory patients, too. Finally, the planning of discharge medications needs a balancing act between the requirements for provision of good analgesia and the risk of opioids going out into the community.
\end{abstract}

Keywords: ambulatory surgery, short-stay surgery, multimodal analgesia, nonopioids, local anesthetics, regional anesthesia

\section{Introduction}

There is a worldwide and ever-increasing trend toward performance of surgery in day- or short-stay settings as so-called ambulatory surgery. This progress has resulted in increasingly complex and major surgery being performed in this setting, partially driven by global economic pressures on our health care systems. ${ }^{1}$ As a consequence of this development, more and more complex procedures are performed in older, almost geriatric, or chronically impaired patients including more with ASA (American Society of Anesthesiologists) 3 status than ever before.

This means also that more patients after potentially more painful procedures are going home within 24 hours of surgery than ever before. Lack of adequate postoperative pain management becomes one important limiting factor on which operations can be performed in an ambulatory setting; another one may be the adverse effects of more aggressive analgesia, eg, postoperative nausea and vomiting (PONV) increasing with increasing opioid requirements leading to increased rates of readmission.

\footnotetext{
Correspondence: Stephan A Schug

Pharmacology, Pharmacy and Anesthesiology Unit, The University of Western Australia, Level 2, MRF Building, Royal Perth Hospital, GPO Box X2213,

Perth 6847, WA, Australia

Tel +6I 892240201

Fax +6I 892240279

Email stephan.schug@uwa.edu.au
}

\section{rates of readmission.}

submit your manuscript | www.dovepress.com

Dovepress

http://dx.doi.org/10.2147/AA.S54869
Ambulatory Anesthesia 2015:2 II-20

(c) (i) (-) 2015 Schug and Chandrasena. This work is published by Dove Medical Press Limited, and licensed under Creative Commons Attribution - Non Commercial (unported, v3.0) License. The full terms of the license are available at http://creativecommons.org/licenses/by-nc/3.0/. Non-commercial uses of the work are permitted Limited. Information permission from Dove Medical Press Limited, provided the work is properly attributed. Permissions beyond the scope of the License are administered by Dove Medical Press Limited. Information on how to request permission may be found at: http://www.dovepress.com/permissions.php 
This review addresses the challenges posed by these relatively new scenarios and show some of the solutions that have been developed.

\section{Quality of pain relief after ambulatory surgery}

A considerable number of studies have looked at the quality of analgesia in the ambulatory surgery setting, and overall the results are rather disappointing and disenchanting.

Pain after discharge remains the most common complication after ambulatory surgery. This has been shown only a few years ago in two large Swedish surveys, as well as in a general ${ }^{2}$ pediatric population. ${ }^{3}$ Similar findings were reported in selected populations, eg, after urological surgery in Spain. ${ }^{4}$ A prospective study after day-case laparoscopic cholecystectomy identified that, after 24 hours, $65 \%$ of patients reported moderate and $23 \%$ severe pain. ${ }^{5}$ Even after operations usually considered as not very painful, such as laparoscopic gynecological surgery, only $60 \%$ of the patients were satisfied with their pain relief. ${ }^{6}$ And these disappointing data continue through to cataract day-stay surgery, where $10 \%$ of patients reported ocular pain at 24 hours, $9 \%$ at 7 days, and $7 \%$ at 6 weeks. ${ }^{7}$

As already alluded to above, these results are not limited to adults but also mirrored in pediatric studies. Here, ear-nose-throat (ENT) procedures have been looked at in detail; eg, after adenotonsillectomy, $52 \%$ of children had a pain score $>5 / 10$ on day 3 and $30 \%$ on day $7 .{ }^{8}$ It is of note here that in a comparison of day-stay versus overnight inpatient stay, pain scores during the first 24 hours were only slightly increased for day-stay patients, and that the maximum pain scores at 24 hours and 7 days were similar. ${ }^{9}$ This is contradicted by another audit, which found pain reports to be significantly higher at home than in the hospital. ${ }^{10}$ Pain relief needs to also be provided for an extended period of time at home; the majority of children after tonsillectomy required at least one analgesic medication for 7 days after surgery. ${ }^{11}$

\section{Adverse effects of pain after ambulatory surgery}

Poor analgesia after any surgery is unacceptable and distressing to patients. This is even more so in an ambulatory setting, where patients have limited access to health care providers and analgesic medications. As a consequence, they may feel abandoned. Callbacks to the surgical center and/or family practitioners and/or emergency departments and readmissions are the result; the most common reason for unplanned hospital admission after ambulatory surgery is unrelieved pain. ${ }^{12,13}$ Poor analgesia at home may lead to sleep disturbance and limited early mobilization, thereby impairing early return to normal function and work. ${ }^{14}$

Last, but not least, exposure to severe pain can cause adverse long-term effects in adults as well as in children. ${ }^{15} \mathrm{Up}$ to $50 \%$ of adults develop chronic pain subsequent to surgery and trauma, with severity of acute pain a major predictive factor ${ }^{16}$ similar effects have been reported in children. ${ }^{17}$

But the consequences of inadequate analgesia begin much earlier after the operation when this issue delays patient discharge; here again, pain was the most common cause of delayed recovery ( $24 \%$ of patients).${ }^{18}$ While opioids can cause nausea and vomiting, uncontrolled pain is also a major cause, often leading to extended stay in the recovery room. ${ }^{19,20}$

All these adverse effects of unrelieved pain have not only human consequences but also economic ones because delays in discharge and readmissions are costly. ${ }^{21}$ Finally, the medicolegal consequences of poor analgesia need to be recognized. ${ }^{22}$

Therefore, the challenge of provision of analgesia after ambulatory surgery needs to be accepted and solutions need to be found.

\section{Reasons for poor analgesia after ambulatory surgery}

The failures to provide sufficient analgesia described above occur despite a wide body of evidence for the best approaches to management of acute pain and despite the clinical availability of a wide range of excellent analgesic drugs. ${ }^{23}$ One potential cause for the lack of improvement in this area has been identified by German surveys as poor adherence to such guidelines for acute pain therapy. ${ }^{24,25}$ This phenomenon has been described as being due to the "disconnect" between the significant scientific advances in the area of multimodal analgesia and the lack of implementation of these concepts into routine clinical practice, in an editorial by White. ${ }^{26}$ This editorial highlights a number of relevant issues in this setting, such as the extensive reliance on opioids leading to complications and the lack of continuation of analgesic therapies into the post-discharge period.

However, improving things is not always easy, as extensively shown in the pediatric literature. Here, barriers against good analgesia have been identified as parental, child, medication, and system factors. ${ }^{27}$ However, overcoming these barriers is not easy because differences in parental attitudes, understanding and access to medications, nausea, or fear of side effects are relevant contributing factors. Attempts to address such problems by supplying a discharge medication 
package $^{28}$ or telephone follow-up by nurses failed after ambulatory tonsillectomy. ${ }^{29}$

\section{General strategies to improve analgesia}

In view of the above shortcomings, and to address current deficits in the management of acute pain after ambulatory surgery, a most recent review has suggested a practical three-step approach. ${ }^{30}$ The suggested steps are 1) identification of highrisk patients, 2) implementation of multimodal analgesic strategies, and 3) ready availability of rescue analgesic regimens.

With regard to identification of high-risk patients, a review recommends a number of issues to be considered in the preoperative assessment, as they will increase the risk of poor pain control postoperatively. ${ }^{30}$ These include a past history of increased preoperative pain (eg, patients with chronic pain) as well as the observation of increased preoperative anxiety. Younger patients and females are also at increased risk. These proposals are supported by data that show preoperative pain to be best predictive factor of postoperative pain. ${ }^{31}$

Finally, the type of surgery is important, as there are now data that certain operations including appendectomy, cholecystectomy, hemorrhoidectomy, and tonsillectomy as well as longer lasting operations lead to more postsurgical pain. The latter point is in line with increasing interest in procedurespecific pain management ${ }^{32}$ such evidence-based, procedurespecific guidelines for a number of operations are available at the PROSPECT website (http://www.postoppain.org). An example from the ambulatory setting would be adenoidectomy and adenotonsillectomy, two common day-case procedures done in children, which frequently cause significant postoperative pain. Following adenoidectomy, acetaminophen may suffice, whereas adenotonsillectomy causes significantly more pain requiring at least a combination of acetaminophen with a nonsteroidal anti-inflammatory drug (NSAID).$^{33}$ Last, but not least, failure of a specific analgesic regimen requires rapid implementation of a rescue strategy. ${ }^{30}$

The importance of evidence-based, multimodal analgesic regimens extending longer into the postoperative period has been highlighted in recent literature, and it is suggested that more future studies on this topic should be undertaken. ${ }^{34}$

\section{Concept of multimodal analgesia}

Multimodal or balanced analgesia, a concept developed around 20 years ago, ${ }^{35}$ has become the something of a gold standard for postoperative pain management. Underpinning this concept has been the idea to use more than one analgesic compound or modality of pain control. Combinations of different medications with different mechanisms of action and/or working at different sites along the pain pathway are used to obtain additive (or even synergistic) pain relief, while leading to an opioid-sparing effect and thereby minimizing adverse effects.

The concept of multimodal analgesia is now widely supported by the literature and in recent guidelines. ${ }^{23,30}$ The new practice guidelines for acute pain management in the perioperative setting by the American Society of Anesthesiologists' Task Force on Acute Pain Management state specifically that, whenever possible, anesthesiologists should use multimodal pain management therapy including regional blocks and an around-the-clock regimen of Cox-2 Inhibitors (coxibs) or nonselective NSAIDs and/or acetaminophen. ${ }^{36}$ Such multimodal analgesia with an emphasis on nonopioids and local anesthetics is a promising concept. This is true in particular after ambulatory surgery, where classical adverse effects of opioids such as nausea and vomiting can delay discharge and increase readmission rates. ${ }^{37}$ In the setting of ambulatory surgery, after incomplete pain relief as discussed above, adverse effects of opioids are the second most common cause for readmission of patients. ${ }^{38} \mathrm{~A}$ good example of the benefits of even avoiding weak opioids such as codeine by combining nonopioids (acetaminophen and ibuprofen) is a trial in which patients in the nonopioid group were more satisfied with their analgesia and had fewer side effects. ${ }^{39}$

Combinations for which benefits along the concept of multimodal analgesia have been identified include acetaminophen, NSAIDs and coxibs, alpha-2-delta modulators (gabapentin and pregabalin), $N$-methyl-D-aspartate (NMDA) receptor antagonists (ketamine), alpha-2 receptor agonists (such as clonidine and dexmedetomidine), and local anesthetics. ${ }^{40}$

\section{Analgesics Nonopioid analgesics}

Acetaminophen, nonselective NSAIDs, and COX-2 selective NSAIDs (coxibs) have become the mainstay of the background analgesia in a multimodal analgesia approach to postoperative pain in all surgical settings. ${ }^{41}$

Acetaminophen is obviously the weakest of the nonopioid analgesics..$^{42}$ However, it has also a very low rate of adverse effects, as long as used in therapeutic doses $<4 \mathrm{~g} /$ day, and nearly no contraindications. ${ }^{43}$ It is therefore not surprising that it is the most commonly used background analgesic in multimodal approaches. In a survey of analgesia after ambulatory surgery in Sweden, it was used in $95 \%$ of cases. ${ }^{2}$ There are 
even minor surgical interventions performed in an ambulatory setting where acetaminophen may be a sufficient analgesic on its own; in a study, $82 \%$ of patients in such a setting were satisfied or very satisfied with acetaminophen as their only analgesic. ${ }^{44}$ This study used intravenous acetaminophen, which is more costly than oral administration, but may be particularly useful for perioperative administration. In an interesting metaanalysis, perioperative intravenous acetaminophen (best given before surgery) resulted in significant reduction of PONV. Finally, acetaminophen can be combined with NSAIDs, and this combination provides analgesia superior to each single drug. ${ }^{45}$ This is the simplest form of multimodal analgesia and has been specifically demonstrated for the combination of acetaminophen with ibuprofen. ${ }^{46}$

Nonselective NSAIDs and coxibs are significantly more effective than acetaminophen with much lower numbers-needed-to-treat (NNTs) in the range 1.7-2.7.42 There are no differences in efficacy between NSAIDs and coxibs here. The role of these nonopioids as a component of multimodal analgesia is well established, with clear demonstration of improved analgesia, reduced opioid requirements, and, thereby, reduced adverse effects such as nausea, vomiting, and sedation. ${ }^{47}$ The use of ibuprofen (120 mg/day) or celecoxib (400 mg/day) for 4 days after ambulatory surgery reduced the need for breakthrough analgesia in the early postdischarge period, leading to improved patient satisfaction and quality of recovery. ${ }^{48}$ Whenever they are not contraindicated, these drugs should be a component of any multimodal analgesic regimen in the ambulatory setting.

However, adverse effects limit the use of NSAIDs in particular. Coxibs with their reduced adverse event profile offer an advantage here; their benefits include reduced gastrointestinal ulceration, lack of platelet inhibition with reduced perioperative blood loss, and lack of induction of bronchospasm in patients with aspirin-exacerbated respiratory disease. ${ }^{49}$ The advantages of coxibs with regard to reduced gastrointestinal ulceration do not only become obvious in the chronic setting, but they are even superior to NSAIDs when combined with a proton pump inhibitor. ${ }^{50}$ Even in the acute setting of short-term use (5-7 days), NSAIDs such as ketorolac and naproxen cause gastric ulcerations in 20\%-40\% of cases, while coxibs have a rate similar to placebo. ${ }^{49}$ While a number of studies and meta-analyses show an increased risk of postoperative bleeding with perioperative NSAIDs, ${ }^{47,51}$ coxibs show a reduced risk compared to NSAIDs ${ }^{52}$ and blood loss identical to placebo. ${ }^{53}$

In countries where available, the intravenously injectable coxib, parecoxib, might be particularly useful, as it permits perioperative use. The cardiovascular safety of this compound in the perioperative setting has been confirmed in a meta-analysis with no increased risk of cardiovascular events compared to placebo. ${ }^{54}$ After ambulatory laparoscopic cholecystectomy, pre- or intraoperatively administered parecoxib was associated with less pain and analgesic requirements leading to shorter times to attain recovery room and hospital discharge criteria compared to placebo. ${ }^{55}$

The most important safety consideration for the use of any NSAIDs is their effect on renal function. While their shortterm use causes only transient reduction in renal function of no relevance in patients with normal renal function, ${ }^{56}$ use in patients with impaired renal function or risk factors such as hypotension/hypovolemia or concomitant use of other nephrotoxic agents increases the risk.

In countries where available, metamizol (dipyrone) is another valuable nonopioid for the ambulatory surgical setting. It is highly effective, ${ }^{57}$ has an additional spasmolytic effect, ${ }^{58}$ and has very little adverse effects with regard to the gastrointestinal, cardiovascular, and renal systems. ${ }^{59}$ There is ongoing debate on the extremely low risk of agranulocytosis, which has resulted in it being registered only in a limited number of countries worldwide. ${ }^{59}$ However, it is recommended and used widely in countries where available, such as The Netherlands, Austria, and Germany. ${ }^{41}$

Overall, all nonopioids are a very useful component of multimodal analgesia after ambulatory surgery and can contribute to improved analgesia and reduced opioid side effects through their opioid-sparing effects. The selection of the most suitable nonopioid for a specific patient should be governed by the severity of pain, comorbidities, and, thereby, contraindications and drug availability in the respective setting. ${ }^{41}$

\section{Opioid analgesics}

Opioids play an important role as analgesics in the immediate perioperative period and as rescue analgesic in ambulatory anesthesia. As mentioned before, multimodal analgesia helps to minimize opioid requirements and thereby opioid related adverse effects such as sedation, nausea, vomiting, and constipation, which may have negative effects on early recovery (affecting discharge from recovery room and from hospital) and resumption of normal activities. ${ }^{37}$

A specific recent concern has developed based on reports of death or opioid-induced ventilatory impairment (OIVI) after codeine use in children. The risk is linked to genetically predisposed ultrarapid metabolization of codeine to morphine (cytochrome P450 2D6-dependent) and in particular 
increased after tonsillectomy and/or adenoidectomy (most commonly performed in an ambulatory setting).$^{60}$ The reason is obviously that children who need this operation often have sleep-disordered breathing; a boxed warning by the FDA on codeine in children after tonsillectomy and adenoidectomy is now in place. ${ }^{61}$

\section{Co-analgesics}

\section{Alpha-2-delta modulators (gabapentin, pregabalin)}

In general, gabapentin and pregabalin have become important components of multimodal analgesia. Usually administered as a premedication, they do not only provide preoperative sedation and anxiolysis but have also beneficial effects with regard to improved analgesia, reduced opioid requirements, and thereby reduced adverse effects of opioids, in particular PONV. ${ }^{62,63}$ The reduction of PONV might even be a specific effect of these compounds. ${ }^{64}$ While these benefits have been shown in some specific surgical settings such as after hysterectomy ${ }^{65}$ and lumbar spinal surgery, ${ }^{66}$ specific studies in the ambulatory setting are limited.

These limited studies have given some contradictory results. For minor gynecological surgery, $100 \mathrm{mg}$ pregabalin had no benefit, suggesting that its role may be in more invasive settings.$^{67}$ In contrast, after laparoscopic hysterectomy, $150 \mathrm{mg}$ pregabalin improved analgesia. ${ }^{68}$ Similarly, after ambulatory laparoscopic cholecystectomy, 1200-1600 mg gabapentin resulted in better analgesia than $15 \mathrm{mg}$ meloxicam. ${ }^{69} \mathrm{In}$ this study, an interesting result was that a combination of gabapentin and meloxicam was not superior to the single medications, suggesting that it might not always be useful to combine multiple modalities. This seems also to be the case when $800 \mathrm{mg}$ gabapentin did not improve analgesia provided by a brachial plexus block for arthroscopic shoulder surgery; ${ }^{70}$ possibly a nerve block results in such good analgesia that this cannot be improved by gabapentin.

In the day-care setting, there is understandably concern about the sedating effect of these drugs impairing recovery and discharge. In a study specifically looking at this, $300 \mathrm{mg}$ pregabalin as a premedication prior to ambulatory orthopedic surgery reduced preoperative anxiety and opioid requirements without persisting sedation impairing discharge. ${ }^{71}$

Overall, gabapentin and pregabalin may provide anxiolysis and improved analgesia in the ambulatory setting and are recommended here; ${ }^{30}$ they might be of particular benefit after more than minor surgery and further studies in this setting are needed.

\section{Corticosteroids}

In general, there is increasing interest in the use of perioperative corticosteroids, most commonly dexamethasone, to reduce PONV originally ${ }^{72}$ but now also with increasing evidence for an analgesic effect. ${ }^{73}$ The latter meta-analysis identified the following benefits from perioperative dexamethasone use: reduction of postoperative pain, opioid consumption, time to first analgesia, requirements for rescue analgesia, and stay in the post-anesthesia care unit.

As these advantages would be of significant benefit in an ambulatory surgery setting, it is not surprising that similar results were found in this setting, eg, after ambulatory gynecological surgery. ${ }^{74}$ In view of the low risk of adverse effects with a single perioperative dose of dexamethasone (4-10 mg), the use of this compound as a component of multimodal analgesia can be recommended in the ambulatory setting.

\section{Local and regional anesthesia techniques}

Local and regional anesthesia techniques are highly recommended as an integral part of multimodal analgesia, eg, in the recent US guidelines. ${ }^{36}$ These techniques are able to offer specific benefits to patients after ambulatory surgery. The techniques cover simple local anesthetic infiltration via single dose ("single-shot") administration, often combined with adjuvants to continuous peripheral nerve blockade (CPNB), increasingly continued for a period after discharge. ${ }^{75}$

\section{Local and peritoneal infiltration}

Simple infiltration and instillation techniques can be quite useful in providing analgesia with minimal adverse effects after ambulatory surgery. Settings where this has been shown to be effective include wound infiltration after hernia repair, ${ }^{76}$ mid-foot infiltration after hallux valgus repair, ${ }^{77}$ and infiltration of trocar sites with local anesthetic after laparoscopic cholecystectomy. ${ }^{78}$ Here, intraperitoneal local anesthetic instillation was also effective, and the combination of both techniques offered further benefits. Intraperitoneal use was also effective after laparoscopic gynecologic surgery. ${ }^{79}$ However, the duration of these effects is limited; maybe this shortcoming can be overcome by use of new slow-release preparations of local anesthetics such as liposomal bupivacaine..$^{80,81}$

\section{Single-dose peripheral nerve blockade}

The benefits of peripheral nerve blocks after ambulatory surgery are not debatable, and many trials in many settings show excellent analgesia with minimal adverse events. ${ }^{82}$ 
Classical uses here include ilioinguinal and iliohypogastric nerve blocks for hernia repair in adults ${ }^{83}$ and children, ${ }^{84}$ paravertebral blocks for breast surgery, ${ }^{85}$ transversus abdominis plane (TAP) blocks after laparoscopic cholecystectomy, ${ }^{86}$ femoral nerve blocks after anterior cruciate ligament repair, ${ }^{87}$ adductor canal block after arthroscopic meniscectomy, ${ }^{88}$ and a range of brachial plexus blocks for shoulder ${ }^{89}$ and hand surgery. ${ }^{90}$ Pelvic plexus block can be used for ambulatory transrectal ultrasound-guided prostate biopsy ${ }^{91}$ and paracervical block for cervical dilatation and uterine interventions. ${ }^{92}$

To extend the duration and quality of analgesia, adjuvants are often added to single-bolus peripheral nerve blocks, as otherwise the limited duration of effect results in development of pain soon after discharge. This has been recommended in particular in the pediatric setting. ${ }^{93}$ In addition, as local anesthetics impair motor function while providing analgesia, this may impair early ambulation and initiation of physiotherapy. Here, addition of adjuvants such as clonidine, dexamethasone, buphrenorphine, and midazolam may be beneficial. ${ }^{94,95}$

Such beneficial effects have been well demonstrated with dexamethasone as well, if added to caudal local anesthetic ${ }^{96}$ as local anesthetic for brachial plexus block. ${ }^{97}$ Similar data exist on buprenorphine as an adjuvant to intraoral nerve blocks. ${ }^{98}$ A meta-analysis of studies of ketamine added to caudal local anesthetics in children, of which many were performed in an outpatient setting, showed prolonged analgesia without prolonged motor block; ${ }^{99}$ however, the practical usefulness of this finding is limited in view of concerns about the neurotoxicity of neuraxial ketamine. Similar findings of a meta-analysis exist for clonidine, ${ }^{100}$ and there is also a study of dexmedetomidine via the caudal route. ${ }^{101}$ However, the addition of clonidine to local anesthetics for intravenous regional anesthesia has shown no benefits. ${ }^{102}$

Whenever patients are discharged after ambulatory surgery before local anesthetic effects have worn off, attention needs to be paid to potential injury to the numb area (knives, heat, cigarettes). However, such discharges are routine practice and should actually be encouraged in view of the excellent analgesia on transfer and in the first hours at home. In a large follow-up series, this practice was shown to be safe; ${ }^{103}$ however, patients need to be provided with appropriate information.

\section{Continuous peripheral nerve blockade}

Insertion of a catheter while blocking peripheral nerves permits extension of the analgesia by top-up doses or a continuous infusion. While this approach has already become standard practice in in-patient settings, ${ }^{104}$ it is now also used increasingly in an ambulatory setting. ${ }^{82,105}$ Patients are commonly sent home with portable pumps providing a continuous infusion via the peripheral nerve catheter, thereby extending the analgesic effect from the maximum 12-16 hours provided by a single bolus nerve block to a number of days postoperatively, if so desired. These techniques are most commonly used after orthopedic surgery ${ }^{106}$ and have been used for various blocks, including paravertebral, interscalene, intersternocleidomastoid, infraclavicular, axillary, psoas compartment, femoral, fascia iliaca, sciatic/ Labat's, sciatic/popliteal, and tibial techniques. Compared to patients discharged home with systemic analgesics, patients using these techniques reported significantly reduced opioid requirements leading to fewer opioid-related adverse effects, less sleep disturbance, faster functional rehabilitation, and higher overall satisfaction. ${ }^{82,104,105}$ Similar findings were made in the pediatric setting. ${ }^{107}$ Enabling discharge earlier after more complex orthopedic surgery, these techniques have also potential economic advantages. ${ }^{108}$

A few examples of such successful usage are a 2-day interscalene infusion at home after shoulder surgery, ${ }^{109}$ continuous popliteal sciatic nerve block for foot and ankle surgery, ${ }^{110}$ and continuous paravertebral block after short-stay mastectomy. ${ }^{111}$ A more detailed analysis of the routine use of continuous interscalene infusions for shoulder surgery in 300 patients revealed a $4 \%$ rate of failure of the technique after discharge from recovery room, one patient developing a site infection requiring antibiotic treatment, and no permanent neurological deficits. ${ }^{12}$ These results are in line with other large case series. Care needs to be taken to reduce the risk of infection. ${ }^{113}$

With regard to safety, the discharge of patients with continuous peripheral nerve blocks requires certain precautions, but are then described as safe. ${ }^{82}$ As always, intravascular placement of the catheter needs to be avoided and confirmed. While it is important that patients and carers get detailed instructions about the technique, its potential adverse effects, and the care for the catheter and the insertion site, it is strongly recommended that patients have access by phone to an anesthesiologist for advice 24 hours a day. ${ }^{114}$ This requirement is confirmed by case series which show that patients call such a service a considerable number of times to get advice on issues such as equipment malfunction, inadequate analgesia, or problems with catheter removal. ${ }^{114,115}$

Overall, techniques of local and regional analgesia should be used whenever possible; this is not only true in the inpatient but even more so in the ambulatory surgery setting. 
The combination of excellent analgesia with minimal systemic adverse effects and significant reduction of opioid requirements makes these techniques ideal after ambulatory surgery.

\section{Nonpharmacological analgesic techniques}

Nonpharmacological techniques are so commonly used in the setting of sports injuries, the home, and physiotherapy, but possibly underutilized after ambulatory surgery. One reason may also be that these techniques are not well studied. However, cryoanalgesia, ${ }^{116}$ transcutaneous electrical nerve stimulation (TENS), ${ }^{117}$ and acupuncture/acupressure, ${ }^{118,119}$ among others, have been used for acute pain management after ambulatory surgery.

\section{Discharge analgesia after ambulatory surgery}

As outlined above, a major problem with ambulatory surgery is that patients experience pain at home hours or days after discharge. This is not only unacceptable from the point of view of the patients' well-being but has also unwanted consequences such as additional presentations at family practitioners, emergency departments, or even readmissions ${ }^{12,13}$ with significant cost and possibly even medicolegal implications. ${ }^{114}$

Therefore, these patients require careful instruction and supply of sufficient amounts of appropriate analgesics to cover their pain at home, which may even increase when they become more active and start rehabilitation.

Such supply can be provided by prescription or as a discharge analgesia package. ${ }^{120}$

On the other hand, there are increasing concerns that provision of discharge analgesics, in particular opioids, would lead to increased long-term use of such analgesics. ${ }^{121}$ Furthermore, opioids introduced acutely carry other increased risks such as impaired ventilation, in particular when used in obese patients and those with sleep-disordered breathing and/or when combined with benzodiazepines, ${ }^{122}$ and impaired driving ability. ${ }^{123}$ There are recent additional concerns in view of the high rate of prescription of opioid overdoses in many countries; opioid provided to patients on discharge may be used by others or even sold on the black market. Therefore, such risks including the risk of abuse need to be identified, and prescriptions of discharge opioids need to be governed by some appropriate precautions. ${ }^{123}$

These arguments are additional support for the use of multimodal analgesia as the preferred analgesic strategy after ambulatory surgery, with an emphasis on nonopioids and local and regional techniques.

\section{Disclosure}

The Anaesthesiology Unit of the University of Western Australia, but none of the authors personally, has received research and travel funding and speaking and consulting honoraria from bioCSL, Bionomics, Eli Lilly, Grunenthal, Janssen, Mundipharma, Pfizer, Phosphagenics and iX Biopharma within the last 2 years.

\section{References}

1. Pericas JM, Aibar J, Soler N, Lopez-Soto A, Sanclemente-Anso C, Bosch X. Should alternatives to conventional hospitalisation be promoted in an era of financial constraint? Eur J Clin Invest. 2013;43(6):602-615.

2. Segerdahl M, Warren-Stomberg M, Rawal N, Brattwall M, Jakobsson J. Clinical practice and routines for day surgery in Sweden: results from a nation-wide survey. Acta Anaesthesiol Scand. 2008;52(1):117-124.

3. Segerdahl M, Warren-Stomberg M, Rawal N, Brattwall M, Jakobsson J. Children in day surgery: clinical practice and routines. The results from a nation-wide survey. Acta Anaesthesiol Scand. 2008;52(6):821-828.

4. Carrion Lopez P, Cortinas Saenz M, Fajardo MJ, et al. Cirugia ambulatoria en un Servicio de Urologia. Analisis del periodo [Ambulatory surgery in a urology department. Analysis of the period 2003-2006]. Archivos Espanoles de Urologia. 2008;61(3):365-370. Spanish.

5. Kavanagh T, Hu P, Minogue S. Daycase laparoscopic cholecystectomy: a prospective study of post-discharge pain, analgesic and antiemetic requirements. Ir J Med Sci. 2008;177(2):111-115.

6. Lovatsis D, Jose JB, Tufman A, Drutz HP, Murphy K. Assessment of patient satisfaction with postoperative pain management after ambulatory gynaecologic laparoscopy. J Obstet Gynaecol Can. 2007;29(8):664-667.

7. Porela-Tiihonen S, Kaarniranta K, Kokki M, Purhonen S, Kokki H. A prospective study on postoperative pain after cataract surgery. Clin Ophthalmol. 2013;7:1429-1435.

8. Stanko D, Bergesio R, Davies K, Hegarty M, von Ungern-Sternberg BS. Postoperative pain, nausea and vomiting following adeno-tonsillectomy a long-term follow-up. Paediatr Anaesth. 2013;23(8):690-696.

9. Norrington AC, Flood LM, Meek T, Tremlett MR. Does day case pediatric tonsillectomy increase postoperative pain compared to overnight stay pediatric tonsillectomy? A prospective comparative audit. Paediatr Anaesth. 2013;23(8):697-701.

10. Shum S, Lim J, Page T, et al. An audit of pain management following pediatric day surgery at British Columbia Children's Hospital. Pain Res Manag. 2012;17(5):328-334.

11. Stewart DW, Ragg PG, Sheppard S, Chalkiadis GA. The severity and duration of postoperative pain and analgesia requirements in children after tonsillectomy, orchidopexy, or inguinal hernia repair. Paediatr Anaesth. 2012;22(2):136-143.

12. Mattila K, Hynynen M. Day surgery in Finland: a prospective cohort study of 14 day-surgery units. Acta Anaesthesiol Scand. 2009;53(4):455-463.

13. Englbrecht JS, Pogatzki-Zahn EM. Ambulante Schmerztherapie Optimierung der Schmerztherapie nach ambulanten Operationen [Pain management after ambulatory surgery in Germany]. Anasthesiol Intensivmed Notfallmed Schmerzther. 2010;45(1):44-55. German.

14. Strassels SA, Chen C, Carr DB. Postoperative analgesia: economics, resource use, and patient satisfaction in an urban teaching hospital. Anesth Analg. 2002;94(1):130-137.

15. Joshi GP, Ogunnaike BO. Consequences of inadequate postoperative pain relief and chronic persistent postoperative pain. Anesthesiol Clin North America. 2005;23(1):21-36. 
16. Kehlet $\mathrm{H}$, Jensen TS, Woolf CJ. Persistent postsurgical pain: risk factors and prevention. Lancet. 2006;367(9522):1618-1625.

17. Page MG, Stinson J, Campbell F, Isaac L, Katz J. Identification of painrelated psychological risk factors for the development and maintenance of pediatric chronic postsurgical pain. J Pain Res. 2013;6:167-180.

18. Pavlin DJ, Chen C, Penaloza DA, Polissar NL, Buckley FP. Pain as a factor complicating recovery and discharge after ambulatory surgery. Anesth Analg. 2002;95(3):627-634.

19. Eriksson H, Tenhunen A, Korttila K. Balanced analgesia improves recovery and outcome after outpatient tubal ligation. Acta Anaesthesiol Scand. 1996;40(2):151-155.

20. Michaloliakou C, Chung F, Sharma S. Preoperative multimodal analgesia facilitates recovery after ambulatory laparoscopic cholecystectomy. Anesth Analg. 1996;82(1):44-51.

21. Coley KC, Williams BA, DaPos SV, Chen C, Smith RB. Retrospective evaluation of unanticipated admissions and readmissions after same day surgery and associated costs. J Clin Anesth. 2002;14(5):349-353.

22. Cousins MJ, Lynch ME. The Declaration Montreal: access to pain management is a fundamental human right. Pain. 2011;152(12):2673-2674.

23. Macintyre PE, Scott DA, Schug SA, Visser EJ, Walker SM, editors. Acute Pain Management: Scientific Evidence. 3rd ed. Melbourne: Australian and New Zealand College of Anaesthetists; 2010.

24. Lux EA, Stamer U, Meissner W, Moser K, Neugebauer E, Wiebalck A. Postoperative Schmerztherapie nach ambulanten Operationen [Postoperative pain after ambulatory surgery]. Schmerz (Berlin, Germany). 2008;22(2):171-175. German.

25. Lux EA, Stamer U, Meissner W, Wiebalck A. Postoperative Schmerztherapie nach ambulanten Operationen. Eine Befragung der behandelnden Anasthesisten [Postoperative pain management after ambulatory surgery. A survey of anaesthesiologists]. Schmerz (Berlin, Germany). 2011;25(2):191-194. German.

26. White PF. Pain management after ambulatory surgery - where is the disconnect? Can J Anaesth. 2008;55(4):201-207.

27. Dorkham MC, Chalkiadis GA, von Ungern Sternberg BS, Davidson AJ. Effective postoperative pain management in children after ambulatory surgery, with a focus on tonsillectomy: barriers and possible solutions. Paediatr Anaesth. 2014;24(3):239-248.

28. Hegarty M, Calder A, Davies K, et al. Does take-home analgesia improve postoperative pain after elective day case surgery? A comparison of hospital vs parent-supplied analgesia. Paediatr Anaesth. 2013;23(5): 385-389.

29. Paquette J, Le May S, Lachance Fiola J, Villeneuve E, Lapointe A, Bourgault P. A randomized clinical trial of a nurse telephone follow-up on paediatric tonsillectomy pain management and complications. $J A d v$ Nurs. 2013;69(9):2054-2065.

30. Dickerson DM. Acute pain management. Anesthesiol Clin. 2014;32(2): 495-504.

31. Gramke HF, de Rijke JM, van Kleef M, et al. Predictive factors of postoperative pain after day-case surgery. Clin J Pain. 2009;25(6):455-460.

32. Joshi GP, Schug SA, Kehlet H. Procedure-specific pain management and outcome strategies. Best Pract Res Clin Anaesthesiol. 2014; 28(2):191-201.

33. Vons KM, Bijker JB, Verwijs EW, Majoor MH, de Graaff JC. Postoperative pain during the first week after adenoidectomy and guillotine adenotonsillectomy in children. Paediatr Anaesth. 2014;24(5):476-482.

34. White PF, Kehlet H. Postoperative pain management and patient outcome: time to return to work! Anesth Analg. 2007;104(3):487-489.

35. Kehlet H, Dahl JB. The value of "multimodal" or "balanced analgesia" in postoperative pain treatment. Anesth Analg. 1993;77(5):1048-1056.

36. American Society of Anesthesiologists Task Force on Acute Pain Management. Practice guidelines for acute pain management in the perioperative setting: an updated report by the American Society of Anesthesiologists Task Force on Acute Pain Management. Anesthesiology. 2012;116(2):248-273.

37. Elvir-Lazo OL, White PF. Postoperative pain management after ambulatory surgery: role of multimodal analgesia. Anesthesiol Clin. 2010;28(2):217-224.
38. Wu CL, Berenholtz SM, Pronovost PJ, Fleisher LA. Systematic review and analysis of postdischarge symptoms after outpatient surgery. Anesthesiology. 2002;96(4):994-1003.

39. Mitchell A, McCrea P, Inglis K, Porter G. A randomized, controlled trial comparing acetaminophen plus ibuprofen versus acetaminophen plus codeine plus caffeine (Tylenol 3) after outpatient breast surgery. Ann Surg Oncol. 2012;19(12):3792-3800.

40. Young A, Buvanendran A. Recent advances in multimodal analgesia. Anesthesiol Clin. 2012;30(1):91-100.

41. Pogatzki-Zahn E, Chandrasena C, Schug SA. Nonopioid analgesics for postoperative pain management. Curr Opin Anaesthesiol. 2014;27(5):513-519.

42. Moore RA, Derry S, McQuay HJ, Wiffen PJ. Single dose oral analgesics for acute postoperative pain in adults. Cochrane Database Syst Rev. 2011;9:CD008659.

43. Graham GG, Davies MJ, Day RO, Mohamudally A, Scott KF. The modern pharmacology of paracetamol: therapeutic actions, mechanism of action, metabolism, toxicity and recent pharmacological findings. Inflammopharmacology. 2013;21(3):201-232.

44. Gorocs TS, Lambert M, Rinne T, Krekler M, Modell S. Efficacy and tolerability of ready-to-use intravenous paracetamol solution as monotherapy or as an adjunct analgesic therapy for postoperative pain in patients undergoing elective ambulatory surgery: open, prospective study. Int J Clin Pract. 2009;63(1):112-120.

45. Ong CK, Seymour RA, Lirk P, Merry AF. Combining paracetamol (acetaminophen) with nonsteroidal antiinflammatory drugs: a qualitative systematic review of analgesic efficacy for acute postoperative pain. Anesth Analg. 2010;110(4):1170-1179.

46. Derry CJ, Derry S, Moore RA. Single dose oral ibuprofen plus paracetamol (acetaminophen) for acute postoperative pain. Cochrane Database Syst Rev. 2013;6:CD010210.

47. Maund E, McDaid C, Rice S, Wright K, Jenkins B, Woolacott N. Paracetamol and selective and non-selective non-steroidal antiinflammatory drugs for the reduction in morphine-related side-effects after major surgery: a systematic review. Br J Anaesth. 2011;106(3):292-297.

48. White PF, Tang J, Wender RH, et al. The effects of oral ibuprofen and celecoxib in preventing pain, improving recovery outcomes and patient satisfaction after ambulatory surgery. Anesth Analg. 2011;112(2):323-329.

49. Schug SA. The role of COX-2 inhibitors in the treatment of postoperative pain. J Cardiovasc Pharmacol. 2006;47(Suppl 1):S82-S86.

50. Chan FK, Lanas A, Scheiman J, Berger MF, Nguyen H, Goldstein JL. Celecoxib versus omeprazole and diclofenac in patients with osteoarthritis and rheumatoid arthritis (CONDOR): a randomised trial. Lancet. 2010;376(9736):173-179.

51. Elia N, Lysakowski C, Tramer MR. Does multimodal analgesia with acetaminophen, nonsteroidal antiinflammatory drugs, or selective cyclooxygenase- 2 inhibitors and patient-controlled analgesia morphine offer advantages over morphine alone? Meta-analyses of randomized trials. Anesthesiology. 2005;103(6):1296-1304.

52. Hegi TR, Bombeli T, Seifert B, et al. Effect of rofecoxib on platelet aggregation and blood loss in gynaecological and breast surgery compared with diclofenac. Br J Anaesth. 2004;92(4):523-531.

53. Lin J, Zhang L, Yang H. Perioperative administration of selective cyclooxygenase-2 inhibitors for postoperative pain management in patients after total knee arthroplasty. J Arthroplasty. 2013;28(2):207.e2-213. e2.

54. Schug SA, Joshi GP, Camu F, Pan S, Cheung R. Cardiovascular safety of the cyclooxygenase-2 selective inhibitors parecoxib and valdecoxib in the postoperative setting: an analysis of integrated data. Anesth Analg. 2009;108(1):299-307.

55. Shuying L, Xiao W, Peng L, Tao Z, Ziying L, Liang Z. Preoperative intravenous parecoxib reduces length of stay on ambulatory laparoscopic cholecystectomy. Int J Surg. 2014;12(5):464-468.

56. Lee A, Cooper MG, Craig JC, Knight JF, Keneally JP. Effects of nonsteroidal anti-inflammatory drugs on postoperative renal function in adults with normal renal function. Cochrane Database Syst Rev. 2007;(2):CD002765. 
57. Edwards J, Meseguer F, Faura C, Moore RA, McQuay HJ, Derry S. Single dose dipyrone for acute postoperative pain. Cochrane Database Syst Rev. 2010;(9):CD003227.

58. Edwards JE, Meseguer F, Faura C, Moore RA, McQuay HJ. Single dose dipyrone for acute renal colic pain. Cochrane Database Syst Rev. 2002;(4):CD003867.

59. Schug SA, Manopas A. Update on the role of non-opioids for postoperative pain treatment. Best Pract Res Clin Anaesthesiol. 2007;21(1) $15-30$.

60. Racoosin JA, Roberson DW, Pacanowski MA, Nielsen DR. New evidence about an old drug - risk with codeine after adenotonsillectomy. N Engl J Med. 2013;368(23):2155-2157.

61. FDA. Safety review update of codeine use in children; new Boxed Warning and Contraindication on use after tonsillectomy and/or adenoidectomy; 2013. Available from: http://www.fda.gov/Drugs/DrugSafety/ ucm339112.htm.

62. Tiippana EM, Hamunen K, Kontinen VK, Kalso E. Do surgical patients benefit from perioperative gabapentin/pregabalin? A systematic review of efficacy and safety. Anesth Analg. 2007;104(6):1545-1556. Table of contents.

63. Zhang J, Ho KY, Wang Y. Efficacy of pregabalin in acute postoperative pain: a meta-analysis. Br J Anaesth. 2011;106(4):454-462.

64. Guttuso T Jr. Gabapentin's anti-nausea and anti-emetic effects: a review. Exp Brain Res. 2014;232(8):2535-2539.

65. Alayed N, Alghanaim N, Tan X, Tulandi T. Preemptive use of gabapentin in abdominal hysterectomy: a systematic review and meta-analysis. Obstet Gynecol. 2014;123(6):1221-1229.

66. Yu L, Ran B, Li M, Shi Z. Gabapentin and pregabalin in the management of postoperative pain after lumbar spinal surgery: a systematic review and meta-analysis. Spine. 2013;38(22):1947-1952.

67. Paech MJ, Goy R, Chua S, Scott K, Christmas T, Doherty DA A randomized, placebo-controlled trial of preoperative oral pregabalin for postoperative pain relief after minor gynecological surgery. Anesth Analg. 2007;105(5):1449-1453. Table of contents.

68. Jokela R, Ahonen J, Tallgren M, Haanpaa M, Korttila K. A randomized controlled trial of perioperative administration of pregabalin for pain after laparoscopic hysterectomy. Pain. 2008;134(1-2):106-112.

69. Gilron I, Orr E, Tu D, Mercer CD, Bond D. A randomized, double-blind, controlled trial of perioperative administration of gabapentin, meloxicam and their combination for spontaneous and movement-evoked pain after ambulatory laparoscopic cholecystectomy. Anesth Analg. 2009;108(2):623-630.

70. Adam F, Menigaux C, Sessler DI, Chauvin M. A single preoperative dose of gabapentin ( 800 milligrams) does not augment postoperative analgesia in patients given interscalene brachial plexus blocks for arthroscopic shoulder surgery. Anesth Analg. 2006;103(5):1278-1282.

71. Gonano C, Latzke D, Sabeti-Aschraf M, Kettner SC, Chiari A, Gustorff B. The anxiolytic effect of pregabalin in outpatients undergoing minor orthopaedic surgery. J Psychopharmacol. 2011;25(2):249-253.

72. De Oliveira GS Jr, Castro-Alves LJ, Ahmad S, Kendall MC, McCarthy RJ. Dexamethasone to prevent postoperative nausea and vomiting: an updated meta-analysis of randomized controlled trials. Anesth Analg. 2013;116(1):58-74

73. Waldron NH, Jones CA, Gan TJ, Allen TK, Habib AS. Impact of perioperative dexamethasone on postoperative analgesia and side-effects: systematic review and meta-analysis. Br J Anaesth. 2013;110(2): 191-200.

74. De Oliveira GS Jr, Ahmad S, Fitzgerald PC, et al. Dose ranging study on the effect of preoperative dexamethasone on postoperative quality of recovery and opioid consumption after ambulatory gynaecological surgery. Br J Anaesth. 2011;107(3):362-371.

75. Schug SA, Chong C. Pain management after ambulatory surgery. Curr Opin Anaesthesiol. 2009;22(6):738-743.

76. Ausems ME, Hulsewe KW, Hooymans PM, Hoofwijk AG. Postoperative analgesia requirements at home after inguinal hernia repair: effects of wound infiltration on postoperative pain. Anaesthesia 2007;62(4):325-331.
77. Adam F, Pelle-Lancien E, Bauer T, Solignac N, Sessler DI, Chauvin M. Anesthesia and postoperative analgesia after percutaneous hallux valgus repair in ambulatory patients. Ann Fr Anesth Reanim. 2012;31(11):e265-e268.

78. Ahn Y, Woods J, Connor S. A systematic review of interventions to facilitate ambulatory laparoscopic cholecystectomy. HPB (Oxford). 2011;13(10):677-686

79. Marks JL, Ata B, Tulandi T. Systematic review and metaanalysis of intraperitoneal instillation of local anesthetics for reduction of pain after gynecologic laparoscopy. J Minim Invasive Gynecol. 2012;19(5):545-553.

80. Viscusi ER, Sinatra R, Onel E, Ramamoorthy SL. The safety of liposome bupivacaine, a novel local analgesic formulation. Clin J Pain. 2014;30(2):102-110.

81. Tong YC, Kaye AD, Urman RD. Liposomal bupivacaine and clinical outcomes. Best Pract Res Clin Anaesthesiol. 2014;28(1):15-27.

82. Salinas FV, Joseph RS. Peripheral nerve blocks for ambulatory surgery. Anesthesiol Clin. 2014;32(2):341-355.

83. Toivonen J, Permi J, Rosenberg PH. Effect of preincisional ilioinguinal and iliohypogastric nerve block on postoperative analgesic requirement in day-surgery patients undergoing herniorrhaphy under spinal anaesthesia. Acta Anaesthesiol Scand. 2001;45(5):603-607.

84. Abdellatif AA. Ultrasound-guided ilioinguinal/iliohypogastric nerve blocks versus caudal block for postoperative analgesia in children undergoing unilateral groin surgery. Saudi J Anaesth. 2012;6(4):367-372.

85. Abdallah FW, Morgan PJ, Cil T, et al. Ultrasound-guided multilevel paravertebral blocks and total intravenous anesthesia improve the quality of recovery after ambulatory breast tumor resection. Anesthesiology. 2014;120(3):703-713

86. Petersen PL, Stjernholm P, Kristiansen VB, et al. The beneficial effect of transversus abdominis plane block after laparoscopic cholecystectomy in day-case surgery: a randomized clinical trial. Anesth Analg. 2012;115(3):527-533.

87. Wulf H, Lowe J, Gnutzmann KH, Steinfeldt T. Femoral nerve block with ropivacaine or bupivacaine in day case anterior crucial ligament reconstruction. Acta Anaesthesiol Scand. 2010;54(4):414-420.

88. Hanson NA, Derby RE, Auyong DB, et al. Ultrasound-guided adductor canal block for arthroscopic medial meniscectomy: a randomized, double-blind trial. Can J Anaesth. 2013;60(9):874-880.

89. Lin E, Choi J, Hadzic A. Peripheral nerve blocks for outpatient surgery: evidence-based indications. Curr Opin Anaesthesiol. 2013;26(4):467-474.

90. Hadzic A, Arliss J, Kerimoglu B, et al. A comparison of infraclavicular nerve block versus general anesthesia for hand and wrist day-case surgeries. Anesthesiology. 2004;101(1):127-132.

91. Cantiello F, Cicione A, Autorino R, Cosentino C, Amato F, Damiano R. Pelvic plexus block is more effective than periprostatic nerve block for pain control during office transrectal ultrasound guided prostate biopsy: a single center, prospective, randomized, double arm study. J Urol. 2012;188(2):417-421.

92. Tangsiriwatthana T, Sangkomkamhang US, Lumbiganon P, Laopaiboon M. Paracervical local anaesthesia for cervical dilatation and uterine intervention. Cochrane Database Syst Rev. 2013;9:CD005056.

93. Lonnqvist PA. Adjuncts should always be used in pediatric regional anesthesia. Paediatric Anaesthesia. Epub 2014 Sep 17.

94. Johansson A, Hao J, Sjolund B. Local corticosteroid application blocks transmission in normal nociceptive C-fibres. Acta Anaesthesiol Scand. 1990;34(5):335-338.

95. Williams BA. Forecast for perineural analgesia procedures for ambulatory surgery of the knee, foot, and ankle: applying patient-centered paradigm shifts. Int Anesthesiol Clin. 2012;50(1):126-142.

96. Kim EM, Lee JR, Koo BN, Im YJ, Oh HJ, Lee JH. Analgesic efficacy of caudal dexamethasone combined with ropivacaine in children undergoing orchiopexy. Br J Anaesth. 2014;112(5):885-891.

97. Desmet M, Braems H, Reynvoet M, et al. IV and perineural dexamethasone are equivalent in increasing the analgesic duration of a single-shot interscalene block with ropivacaine for shoulder surgery: a prospective, randomized, placebo-controlled study. Br J Anaesth. 2013;111(3):445-452. 
98. Kumar SP, Suryavanshi RK, Kotrashetti SM. Efficacy of buprenorphine added $2 \%$ lignocaine 1:80000 in postoperative analgesia after minor oral surgery. J Maxillofac Oral Surg. 2013;12(1):30-34.

99. Schnabel A, Poepping DM, Kranke P, Zahn PK, Pogatzki-Zahn EM. Efficacy and adverse effects of ketamine as an additive for paediatric caudal anaesthesia: a quantitative systematic review of randomized controlled trials. Br J Anaesth. 2011;107(4):601-611.

100. Schnabel A, Poepping DM, Pogatzki-Zahn EM, Zahn PK. Efficacy and safety of clonidine as additive for caudal regional anesthesia: a quantitative systematic review of randomized controlled trials. Paediatr Anaesth. 2011;21(12):1219-1230.

101. Bharti N, Praveen R, Bala I. A dose-response study of caudal dexmedetomidine with ropivacaine in pediatric day care patients undergoing lower abdominal and perineal surgeries: a randomized controlled trial. Paediatr Anaesth. 2014;24(11):1158-1163.

102. Ivie CS, Viscomi CM, Adams DC, Friend AF, Murphy TR, Parker C. Clonidine as an adjunct to intravenous regional anesthesia: a randomized, double-blind, placebo-controlled dose ranging study. J Anaesthesiol Clin Pharmacol. 2011;27(3):323-327.

103. Klein SM, Nielsen KC, Greengrass RA, WarnerDS, MartinA, Steele SM. Ambulatory discharge after long-acting peripheral nerve blockade: 2382 blocks with ropivacaine. Anesth Analg. 2002;94(1):65-70.

104. Ilfeld BM. Continuous peripheral nerve blocks: a review of the published evidence. Anesth Analg. 2011;113(4):904-925.

105. Ilfeld BM. Continuous peripheral nerve blocks in the hospital and at home. Anesthesiol Clin. 2011;29(2):193-211.

106. O'Donnell BD, Iohom G. Regional anesthesia techniques for ambulatory orthopedic surgery. Curr Opin Anaesthesiol. 2008;21(6):723-728.

107. Gurnaney H, Kraemer FW, Maxwell L, Muhly WT, Schleelein L, Ganesh A. Ambulatory continuous peripheral nerve blocks in children and adolescents: a longitudinal 8-year single center study. Anesth Analg. 2014;118(3):621-627.

108. Ilfeld BM, Mariano ER, Williams BA, Woodard JN, Macario A. Hospitalization costs of total knee arthroplasty with a continuous femoral nerve block provided only in the hospital versus on an ambulatory basis: a retrospective, case-control, cost-minimization analysis. Reg Anesth Pain Med. 2007;32(1):46-54.

109. Mariano ER, Afra R, Loland VJ, et al. Continuous interscalene brachial plexus block via an ultrasound-guided posterior approach: a randomized, triple-masked, placebo-controlled study. Anesth Analg. 2009;108(5):1688-1694.

110. Borgeat A, Blumenthal S, Lambert M, Theodorou P, Vienne P. The feasibility and complications of the continuous popliteal nerve block: a 1001-case survey. Anesth Analg. 2006;103(1):229-233.
111. Ilfeld BM, Madison SJ, Suresh PJ, et al. Treatment of postmastectomy pain with ambulatory continuous paravertebral nerve blocks: a randomized, triple-masked, placebo-controlled study. Reg Anesth Pain Med. 2014;39(2):89-96.

112. Fredrickson MJ, Ball CM, Dalgleish AJ. Successful continuous interscalene analgesia for ambulatory shoulder surgery in a private practice setting. Reg Anesth Pain Med. 2008;33(2):122-128.

113. Capdevila X, Bringuier S, Borgeat A. Infectious risk of continuous peripheral nerve blocks. Anesthesiology. 2009;110(1):182-188.

114. Swenson JD, Bay N, Loose E, et al. Outpatient management of continuous peripheral nerve catheters placed using ultrasound guidance: an experience in 620 patients. Anesth Analg. 2006;103(6):1436-1443.

115. Ilfeld BM, Morey TE, Enneking FK. Continuous infraclavicular brachial plexus block for postoperative pain control at home: a randomized, double-blinded, placebo-controlled study. Anesthesiology. 2002;96(6):1297-1304.

116. Barber FA, McGuire DA, Click S. Continuous-flow cold therapy for outpatient anterior cruciate ligament reconstruction. Arthroscopy. 1998;14(2):130-135.

117. Yilmazer M, Kose S, Arioz DT, Koken G, Ozbulut O. Efficacy of transcutaneous electrical nerve stimulation for pain relief in women undergoing office endometrial biopsy. Arch Gynecol Obstet. 2012;285(4):1059-1064.

118. Felhendler D, Lisander B. Pressure on acupoints decreases postoperative pain. Clin J Pain. 1996;12(4):326-329.

119. Zhang Q, Gao Z, Wang H, et al. The effect of pre-treatment with transcutaneous electrical acupoint stimulation on the quality of recovery after ambulatory breast surgery: a prospective, randomised controlled trial. Anaesthesia. 2014;69(8):832-839.

120. Stomberg MW, Brattwall M, Jakobsson JG. Day surgery, variations in routines and practices a questionnaire survey. Int J Surg. 2013; 11(2):178-182.

121. Alam A, Gomes T, Zheng H, Mamdani MM, Juurlink DN, Bell CM. Long-term analgesic use after low-risk surgery: a retrospective cohort study. Arch Intern Med. 2012;172(5):425-430.

122. Macintyre PE, Loadsman JA, Scott DA. Opioids, ventilation and acute pain management. Anaesth Intensive Care. 2011;39(4):545-558.

123. Macintyre PE, Huxtable CA, Flint SL, Dobbin MD. Costs and consequences: a review of discharge opioid prescribing for ongoing management of acute pain. Anaesth Intensive Care. 2014;42(5):558-574.
Ambulatory Anesthesia

\section{Publish your work in this journal}

Ambulatory Anesthesia is an international, peer reviewed, open access journal publishing articles that address all aspects of ambulatory anesthesia practice, in particular: anesthetic techniques, sedation and safety practices, pharmacokinetics, preoperative evaluation, analgesia interventions, regulatory and compliance issues, postoperative recovery,

Submit your manuscript here: http://www.dovepress.com/ambulatory-anesthesia-journal

\section{Dovepress}

patient satisfaction, administrative topics, and cost analysis themes. The manuscript management system is completely online and includes a very quick and fair peer review system, which is all easy to use. Visit http://www.dovepress.com/testimonials.php to read real quotes from published authors. 